\section{(2) OPEN ACCESS}

\title{
Extracavitary primary effusion lymphoma recurring with syphilis in an HIV-infected patient
}

\author{
Darakhshan Sohail Ahmed, ${ }^{1,2}$ Marc Poliquin, ${ }^{3}$ Louis-André Julien, ${ }^{4}$ Jean-Pierre Routy, ${ }^{5,6}$
}

${ }^{1}$ Infectious Diseases and Immunity in Global Health Program, Research Institute of the McGill University Health Centre, Montreal, Quebec, Canada

${ }^{2}$ Division of Hematology and Chronic Viral Illness Service, McGill University Health Centre, Montreal, Quebec, Canada ${ }^{3}$ Clinique médicale L' Agora, Montreal, Quebec, Canada ${ }^{4}$ Department of Pathology, McGill University Health Centre, Montreal, Quebec, Canada ${ }^{5}$ Department of Medicine, Research Institute of the McGill University Health Centre, Montreal, Quebec, Canada ${ }^{6}$ Division of Haematology, McGill University Health Centre, Montreal, Quebec, Canada

\section{Correspondence to}

Dr Jean-Pierre Routy; jean-pierre.routy@mcgill.ca

Accepted 8 October 2020

Check for updates

(c) BMJ Publishing Group Limited 2020. Re-use permitted under CC BY-NC. No commercial re-use. See rights and permissions. Published by BMJ.

To cite: Sohail Ahmed $D$, Poliquin M, Julien L-A, et al. BMJ Case Rep

2020:13:e235204.

doi:10.1136/bcr-2020-

235204

\section{SUMMARY}

A 59-year-old Caucasian man infected with HIV, in remission from human herpes virus-8-positive extracavitary primary effusion lymphoma (EC-PEL), presented to a sexual health clinic with fever and rectal pain 10 weeks after a single episode of receptive anal sexual intercourse with another man. He was initially treated for a presumptive diagnosis of lymphogranuloma venereum proctitis, then for syphilis on positive serology. Rectosigmoidoscopy revealed a single ulcerated rectal mass; endoscopic biopsies confirmed the recurrence of EC-PEL. The patient received chemotherapy and went into remission. This is the first reported case of EC-PEL occurring synchronously with early syphilis, and specifically at the site of inoculation, which can be a major diagnostic challenge since both conditions may present with lymphadenopathy, mucosal involvement and constitutional symptoms. We reviewed the literature for similar cases and hypothesised that syphilis may have triggered the recurrence of this rare lymphoma.

\section{BACKGROUND}

Primary effusion lymphoma (PEL) is a very aggressive rare subtype of large $B$ cell lymphoma ${ }^{12}$ with a median survival of less than a year. ${ }^{34}$ This lymphoma usually occurs in individuals infected with HIV $^{4} 5$ and among recipients of organ transplants. ${ }^{6-8}$ Human herpes virus-8 (HHV8)/Kaposi sarcoma-associated herpesvirus (KSHV) is an oncogenic virus involved in all cases of PEL, with $80 \%$ concomitant association with Epstein-Barr virus (EBV). ${ }^{9}$ Conversely, while HIV-negative patients with PEL from HHV8 endemic areas such as the Mediterranean are older, EBV infection occurs in only $50 \%$ of cases and is associated with more extracavitary involvement. ${ }^{10} 11$ PEL typically presents as a malignant effusion in the pleural, pericardial or peritoneal cavities. ${ }^{3}$ However, in 5\% of cases, ${ }^{2}$ lymphomas otherwise indistinguishable from PEL presenting as solid tumour masses outside body cavities have been recognised by the WHO revised fourth edition as the extracavitary variant of PEL (EC-PEL). ${ }^{12}$ EC-PEL most commonly presents in the lymph nodes and $\operatorname{skin}^{313}$; however, cases of gastrointestinal involvement $t^{5}{ }^{14-17}$ have been reported and their outcome seems to be better than the effusion variant. ${ }^{3}$

Syphilis, a sexually transmitted disease caused by the bacterium Treponema pallidum, is a source of substantial morbidity, complications and adverse outcomes. $^{18}$ Syphilis is a major public health concern as the number and rates of reported cases are rising dramatically in Western Europe and the Americas, ${ }^{18}$ including Canada, where they have more than doubled since 2008 and have the highest increase in rates of all sexually transmitted disease. ${ }^{19}$ As syphilis is a great masquerade ${ }^{20}$ and may present as generalised lymphadenopathy and fever, ${ }^{20-22}$ diagnosis of a synchronous lymphoma represents a diagnostic challenge.

The case we present herein illustrates both the very rare occurrence of EC-PEL within the digestive tract and the diagnostic challenge posed by simultaneous early syphilis. To our knowledge, this is the first reported case of EC-PEL occurring synchronously with early syphilis specifically at the site of inoculation. This observation led us to raise the hypothesis that syphilis played a role in the recurrence of this rare lymphoma.

\section{CASE PRESENTATION}

A 59-year-old Caucasian man with a long history of treated HIV infection presented to a sexually transmitted infection (STI) clinic in October 2019 with complaints of rectal pain and fever. He was initially diagnosed with HIV infection in 2010 with a low CD4 T cell count of $60 \times 10^{6} / \mathrm{L}$ and plasma HIV viral load of 151000 copies $/ \mathrm{mL}$ and was successfully treated with emtricitabine, tenofovir and raltegravir. He was later diagnosed with cutaneous Kaposi sarcoma (KS) with bilateral inguinal lymphadenopathy in 2012 and with HHV8-positive but EBV-negative EC-PEL with cutaneous involvement in $2014 .^{2} \mathrm{He}$ was treated with liposomal doxorubicin (LD) for his KS and with four cycles of R-CHOP (rituximab, cyclophosphamide, doxorubicin hydrochloride, oncovin and prednisone) for his lymphoma, as previously described. ${ }^{2}$ His CD4 $\mathrm{T}$ cell count remained below $100 \times 10^{6} / \mathrm{L}$ on the same antiretroviral therapy (ART), and although he had recurrences of his lymphoma (2015-2017) involving the skin and tonsils without lymphadenopathy he had been in remission since October 2017.

His rectal pain developed 3 weeks after a single episode of receptive anal sexual intercourse with another man, precisely on 29 June 2019. On 7 October 2019, he presented to an STI clinic in Montreal with worsening rectal pain, tenesmus, mucoid discharge, constipation alternating with diarrhoea, and fever $\left(38.4^{\circ} \mathrm{C}\right)$. He also complained of severe constitutional symptoms, including drenching night sweats, weight loss (about 9 kilogram) and extreme fatigue. He denied any bright red blood per rectum, melaena or vomiting. Physical examination of his palms, soles, torso, penis, anus, mouth, spleen and lymph nodes was unremarkable, and no lesion or ulcer was identified. 


\begin{tabular}{|c|c|c|c|c|c|c|c|c|}
\hline Laboratory results & $\begin{array}{l}16 \text { May } \\
2019\end{array}$ & $\begin{array}{l}27 \text { September } \\
2019\end{array}$ & 17 October 2019 & 30 October 2019 & 19 December 2019 & $\begin{array}{l}10 \text { January } \\
2020\end{array}$ & $\begin{array}{l}7 \text { February } \\
2020\end{array}$ & 4 August 2020 \\
\hline $\begin{array}{l}\text { Timeline of } \\
\text { evaluation and } \\
\text { intervention }\end{array}$ & $\begin{array}{l}\text { Routine } \\
\text { blood test }\end{array}$ & $\begin{array}{l}\text { Routine blood } \\
\text { test }\end{array}$ & $\begin{array}{l}\text { Injection of } \\
\text { penicillin started }\end{array}$ & $\begin{array}{l}\text { Follow-up blood } \\
\text { test }\end{array}$ & $\begin{array}{l}\text { Follow-up blood } \\
\text { test }\end{array}$ & $\begin{array}{l}\text { LD infused } \\
\text { (first dose) }\end{array}$ & $\begin{array}{l}\text { LD infused } \\
\text { (second dose) }\end{array}$ & Routine blood test \\
\hline $\mathrm{Hb}(\mathrm{g} / \mathrm{L})$ & 147 & 136 & - & 140 & 143 & 150 & 151 & 155 \\
\hline $\mathrm{LDH}(\mathrm{U} / \mathrm{L})$ & ND & 143 & - & ND & 113 & 115 & ND & 145 \\
\hline AST (U/L) & 18 & 69 & - & 14 & 19 & 18 & 38 & 21 \\
\hline$\beta 2 \mathrm{M}(\mathrm{mg} / \mathrm{L})$ & 3.2 & 5.6 & - & 3.7 & 3.5 & 3.2 & 3.2 & ND \\
\hline CRP (mg/L) & ND & 62.8 & - & 1.6 & 1 & 1.3 & 1.2 & 0.9 \\
\hline Creatinine ( $\mu \mathrm{mol} / \mathrm{L})$ & 74 & 75 & - & 70 & 74 & 77 & 83 & ND \\
\hline RPR (titre) & Negative & ND & $1: 128$ & ND & $1: 8$ & $1: 2$ & $1: 2$ & ND \\
\hline CD4 (cells $\times 10^{6} / \mathrm{L}$ ) & 125 & 59 & - & 109 & 113 & ND & ND & ND \\
\hline HIV VL (copies/mL) & $<20$ & $<20$ & - & 56 & $<20$ & ND & 61 & $<20$ \\
\hline HHV8 PCR* & ND & Positive & - & ND & ND & Positive & ND & Negative \\
\hline EBV PCR (copies/mL) & 5248 & ND & - & ND & 5754 & ND & ND & 2239 \\
\hline CMV PCR (copies $/ \mathrm{mL}$ ) & ND & ND & - & ND & $<50$ & ND & ND & ND \\
\hline
\end{tabular}

*HHV8 PCR results were not quantitative.

AST, aspartate aminotransferase; CMV, cytomegalovirus; CRP, C reactive protein; EBV, Epstein-Barr virus; EC-PEL, extracavitary primary effusion lymphoma; Hb, haemoglobin; HHV8, human herpes virus-8; LD, liposomal doxorubicin; LDH, lactate dehydrogenase; $\beta 2 \mathrm{M}, \beta 2$ microglobulin; ND, not done; RPR, rapid plasma reagin; VL, viral load.

\section{INVESTIGATIONS}

On 7 October 2019, the patient underwent serological testing for syphilis, and samples from the throat, anus and penis were collected for sexual screening, including testing for Chlamydia trachomatis and Neisseria gonorrhoeae. Based on clinical presentation, he was treated with doxycycline for suspicion of lymphogranuloma venereum (LGV) proctitis. However, the nucleic acid amplification test (NAAT) for chlamydia and gonorrhoea was negative, excluding LGV proctitis. Testing for syphilis showed a high rapid plasma reagin (RPR) titre of $1: 128$, consistent with early syphilitic infection. Treatment with penicillin was initiated, followed by a decline in fever, night sweats and relief in his constipation, accompanied by a rapid decline in the levels of inflammatory markers such as $\beta 2$ microglobulin, $C$ reactive protein (CRP) and D-dimer $(0.75 \mu \mathrm{g} / \mathrm{mL})$ (table 1$)$. Furthermore, following penicillin treatment, the RPR titre declined from $1: 128$ to $1: 8$ and further to $1: 2$ on 19 December 2019 and 10 January 2020, respectively (table 1) However, T. pallidum was not identified on biopsies by immunohistochemistry performed 10 days after treatment for LGV and syphilis.

The patient underwent rectosigmoidoscopy on 17 October 2019, which revealed a $5 \mathrm{~cm}$ rectal mass, of which multiple biopsies were taken. The patient was also referred to his haematologist at the McGill University Health Centre where he had been followed and treated for his lymphoma. Whole-body positron emission topography/computed topography (PET/CT) scan revealed intense 18-fluorodeoxyglucose (FDG) activity in the rectum and hypermetabolic activity in the left external iliac, porta hepatis and internal mammary lymph nodes, most consistent with a lymphoproliferative process.

Histopathological analysis of the endoscopic biopsies showed fragments of the tissue consistent with ulceration and infiltration by large atypical lymphoid cells (figure 1). Immunohistochemistry revealed that the neoplastic cells were positive for HHV8, Epithelial Membrane Antigen (EMA) and B-cell lymphoma 2 (BCL2) and negative for CD45, CD3, CD20, CD79a, PAX5, BCL6, CD30, CD15 and CD138. Kappa and lambda light chains were negative by in situ hybridisation, ${ }^{23}$ with faint positive lambda light chain by immunohistochemistry. Epstein-Barr Encoding Region (EBER) in situ hybridisation was negative for
EBV. The staining of atypical lymphoid cells was 95\% positive for Ki-67 proliferation index. B cell receptor (BCR) gene rearrangement testing using PCR confirmed the clonality of the atypical B cells. These findings were similar to those from previous biopsies of the known EC-PEL in this patient, ${ }^{2}$ thus consistent with rectal lymphoma relapse. He received doses of LD on 10 January and 7 February 2020 (table 1) and achieved remission of EC-PEL supported by rectosigmoidoscopy examination and PET scan (figure 2).

\section{DIFFERENTIAL DIAGNOSIS}

The presumptive diagnosis of LGV proctitis was tentatively made based on the patient's recent sexual history and presentation with rectal pain, tenesmus and fever. However, given the high RPR titre (1:128) and negative NAAT results for chlamydia and gonorrhoea, a diagnosis of syphilitic proctitis was made, ${ }^{24}$ prompting treatment with penicillin and resulting in improvement of his symptoms and a decline in inflammatory markers (table 1). Only on further investigations, including PET/CT scan, rectosigmoidoscopy and histopathological analysis of the endoscopic biopsies, the diagnosis of synchronous relapse EC-PEL was made, specifically at the site of inoculation with T. pallidum.

HHV8-positive lymphoproliferative disorders other than PEL (or EC-PEL) include HHV8-positive multicentric Castleman's disease, HHV8-positive diffuse large B cell lymphoma and germinotropic lymphoproliferative disorder. ${ }^{12}$ Histologically, the main differential diagnosis of PEL is HHV8-positive diffuse large B cell lymphoma, but the latter usually arises in association with HHV8-positive multicentric Castleman's disease, never present in this patient.

\section{TREATMENT}

The patient had been treated with ART since 2010, with persistently low CD4 T cell count (mean CD4 T cell count of 50-100 cells $/ \mathrm{mL}$ ) and with a plasma HIV viral load below the detection level $(<20$ copies $/ \mathrm{mL})$. The patient received four cycles of R-CHOP for the previous occurrence of his lymphoma and was treated with LD for cutaneous KS lesions with successful remission. ${ }^{2}$ Later recurrences of his EC-PEL 


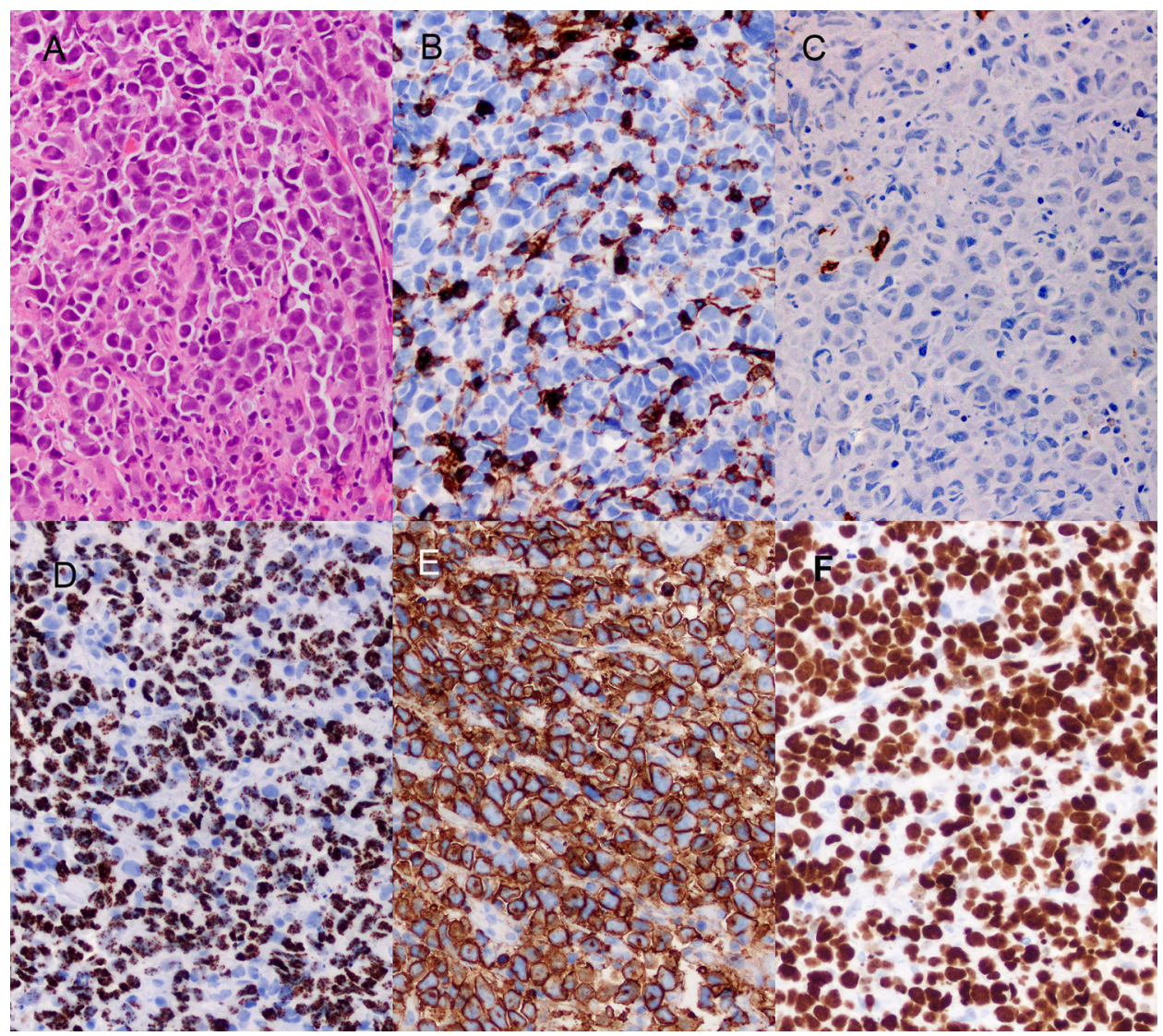

Figure 1 Histology and immunohistochemistry on the biopsies of the rectal mass. Medium power H\&E stain showing diffuse infiltration by large atypical lymphoid cells (A). Immunohistochemistry shows neoplastic cells negative for CD45 (B) and CD20 (C), but positive for HHV8 (D) and Epithelial Membrane Antigen (EMA) (E). The Ki-67 proliferation index is very high (F). All magnifications $\times 200$. HHV8, human herpes virus-8.

in the skin and tonsils were treated with LD only, with unexpected remissions. ${ }^{2}$ At the patient's request and to avoid second-line chemotherapy, LD was thus given between 2014 and 2017 for three recurrences of EC-PEL. The patient's longest period of remission from lymphoma was 25 months, from September 2017 to October 2019, the last recurrence being herein reported.

\section{OUTCOME AND FOLLOW-UP}

Rectosigmoidoscopies performed on 16 January and 5 February 2020 showed rapid regression of the tumour after only one cycle of LD (figure 2). On clinical management and treatment as described above, the patient demonstrated complete clinical and tumorous response and remained asymptomatic, even on his latest visit at the clinic on 27 October 2020.

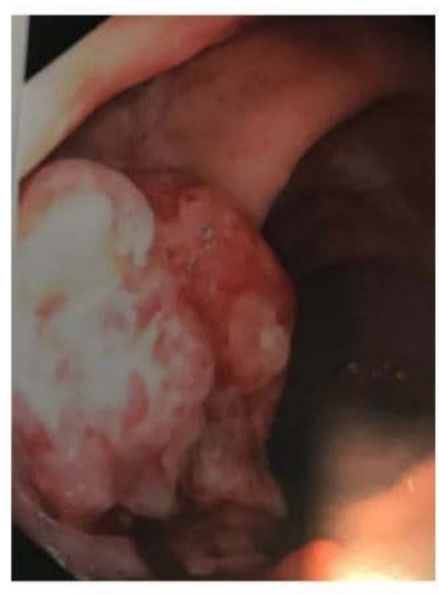

17 October 2019

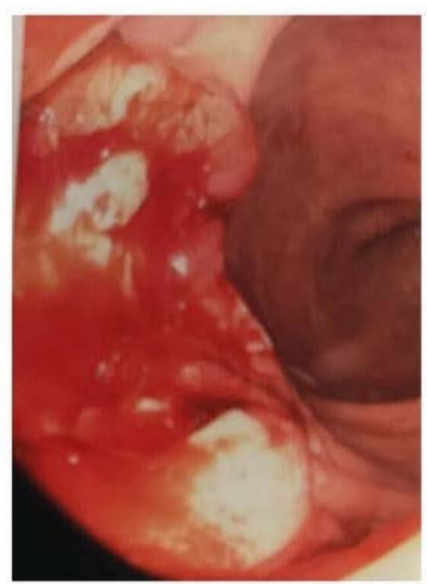

16 January 2020

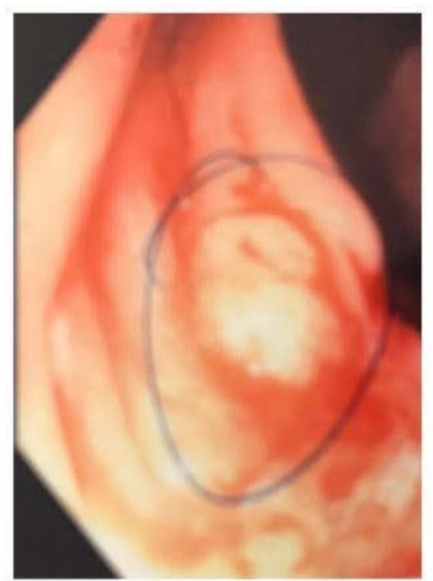

5 February 2020

Figure 2 Images showing the mass on the rectal mucosa before and after treatment with liposomal doxorubicin infusion. 


\section{DISCUSSION}

In immunosuppressed individuals, oncogenic viruses persist in infected cells where they more effectively transformed into malignant cells. HHV8 is a DNA oncovirus that can infect endothelial cells as well as B cells and bring about the malignant transformation of both cell types. Distinct from other herpesviruses, a significant proportion of HHV8-infected cells can produce high levels of a virally encoded interleukin 6 (IL-6), contributing to inflammation and B cell extrafollicular maturation. ${ }^{25}$ When endothelial cells are preferentially infected, KS results; ${ }^{526} 27$ when B cells are infected, ${ }^{26}$ HHV8 creates a fertile epigenetic milieu for B cell dysfunction and establishes a prolymphomagenic environment, which may lead to multicentric Castleman's disease, diffuse large B cell lymphoma or PEL. In individuals living with HIV, two or more of these conditions may develop either simultaneously or independently over time. ${ }^{28}$ Importantly, the precise diagnosis and classification of HHV8associated lymphoproliferative disorders and KS are crucial, as their treatments and prognosis differ markedly.

PEL, a large B cell lymphoma presenting with an inflammatory syndrome, constitutes approximately 4\% of HIV-related lymphomas. Whereas PEL usually presents as effusions in body cavities without identifiable tumour masses, the EC-PEL variant presents as non-cavitary masses most commonly involving the lymph nodes, skin or occasionally digestive tract. Digestive tract and mucosal involvement by EC-PEL is not common and is solely reported in a handful of cases. We reviewed the literature for these cases ${ }^{514-1729}$ and included a summary of their clinicopathological features in table 2. Both PEL and EC-PEL share similar morphological, immunophenotypic and virological characteristics. $^{3}{ }^{30}$ The extrafollicular development of these lymphomas has been demonstrated by class-switching recombination and somatic hypermutation. ${ }^{25}$ Morphology of the malignant cells may show immunoblastic, plasmablastic or anaplastic features. ${ }^{2}$ By immunohistochemistry, they often reveal prominent features of terminally differentiated plasma cells, and the presence of HHV8 in the neoplastic cells is essential for the diagnosis. This lymphoma is also distinctive due to the common lack of expression of pan-B cell markers such as CD20, CD79a and CD19, and therefore may require $\mathrm{BCR}$ gene rearrangement testing to confirm its B cell lineage and clonality. CD45 expression may be low or absent, and activation markers, plasma cell markers and non-lineage-associated antigens are often expressed, including CD30, CD138 and EMA, with rare aberrant expression of T cell-associated antigens. ${ }^{12}$

HIV causes persistent immune dysfunction in B cell follicles due to the absence of $\mathrm{T}$ cell immune surveillance, which in turn contributes to the dysregulation of EBV latency. Therefore, as most cases of PEL and EC-PEL occur in the context of HIV, it is not surprising that over $80 \%$ of these lymphomas are associated with EBV coinfection. ${ }^{9}$ Nevertheless, cases of PEL without EBV coinfection in the neoplastic cells are occasionally reported, as in our patient, although this is most common in elderly non-immunocompromised individuals living in Eastern Mediterranean regions. Despite decades of successful ART and non-detectable HIV plasma viral load, the patient had a low stable CD4 T cell count $\left(100 \times 10^{6} / \mathrm{L}\right)$ and a low CD4:CD8 ratio $(0.4)$, indicating a reduced capacity of immune reconstitution. Interestingly, although EBV could not be demonstrated in the neoplastic cells of his lymphoma by EBER in situ hybridisation, EBV viraemia was present at the time of relapse.

One additional peculiarity of this case is that the exact date of syphilis transmission is known. In fact, the patient acquired syphilis precisely on 29 June 2019, during a single episode of receptive anal intercourse with another man, the only sexual intercourse he had over the past year, as reported. To further emphasise this, a negative RPR titre was also documented in May 2019. The patient presented 4 months after in an STI clinic in Montreal with complaints of rectal pain associated with severe constitutional symptoms and elevated inflammatory indicators, such as increased CRP, ferritin, D-dimer and $\beta 2$ microglobulin (table 1). Medical history and symptomatology were consistent with syphilitic proctitis, and treatment with penicillin resulted in the improvement of symptoms, with a rapid decline in inflammatory markers. However, identification of a $5 \mathrm{~cm}$ ulcerated rectal mass revealed a rectal biopsy-proven recurrence of EC-PEL. The peculiar synchronous onset of rectal syphilis and rectal recurrence of EC-PEL led us to raise the hypothesis that syphilis played a role in the recurrence of this rare lymphoma.

Particularly, we speculate that the prominent inflammation induced by syphilis in the rectal mucosa may have triggered the activation of HHV8-infected B cells, favouring local development of lymphoma. As it is the case for KS, the development of PEL and EC-PEL may be dependent on sustained proinflammatory signals to render B cells more permissive to infection, subsequent activation and proliferation. In addition, using complementary in vitro and in vivo studies, mast cells have been identified as a source of proinflammatory cytokines within the tumour microenvironment. ${ }^{31}$ Consistent with this, treatment with penicillin also led to subsiding digestive symptoms and a drop in inflammatory indicators. The decline in the inflammatory microenvironment may have decreased the pro-tumorous effect of syphilis and may have increased the sensitivity of the tumour cells to chemotherapy. During the last few decades, chronic inflammation, infection, and even commensal bacteria and viruses have been reported at various extent to be associated with the development of certain Non-Hodgkin Lymphomas. ${ }^{23} 3233$

In sum, the concomitant diagnosis of early syphilis and rectal recurrence of EC-PEL in a 59-year-old man living with HIV poses a diagnostic challenge, as both conditions may present with lymphadenopathy, skin involvement and constitutional symptoms. Rectosigmoidoscopy was key in the identification of the tumour and pathological diagnosis of recurring EC-PEL. As the development of virally induced lymphoma depends in part on the immune status of the patient, where both immunosuppression and inflammation may play a role, we consider that the syphilis-induced inflammation was a contributor to the development of the EC-PEL in this patient with low immune reconstitution. This is supported by the 'cytokine strom' occurring during early syphilis. Following its acquisition, T. pallidum is taken up by dendritic cells, which then trafficked it to draining

\section{Learning points}

Syphilis may mimic lymphoma by presenting as generalised lymphadenopathy with constitutional symptoms.

- In this case report, the patient presented with early syphilis concurrently with the recurrence of extracavitary primary effusion lymphoma (EC-PEL) in the rectum, specifically at the site of Treponema pallidum inoculation.

- Rectosigmoidoscopy with biopsy was key in the diagnosis of lymphoma.

- Temporal association and anatomical co-localisation of syphilis and recurring EC-PEL may infer a causal or contributory role to syphilis in lymphomagenesis. 
lymph nodes to present treponemal antigens to naive B cells and $\mathrm{T}$ cells. After priming, activated $\mathrm{T}$ cells secrete interferon $\gamma$, enhancing the production of inflammatory cytokines, such as tumour necrosis factor and IL-6, which in this context may trigger a recurrence of EC-PEL. ${ }^{34}$ It is well established that both HHV8 and human IL-6 contribute to the transformation of infected B cells into PEL. ${ }^{35}$ Globally, IL-6 triggering, temporal association, anatomical co-localisation of syphilis and recurring EC-PEL may infer a causal or contributory role to syphilis in lymphomagenesis during HIV infection.

Acknowledgements We thank the patient for his consent and help in reconstituting his complex medical history. We thank Stephane Isnard, John Lin and Brandon Fombuena for the critical review of this case report. We thank Angie Massicotte for coordination.

Contributors DSA contributed to the planning of the manuscript, reviewed the patient file, performed the literature review and wrote the first and final draft of the manuscript. MP participated in the planning of the manuscript, performed the rectosigmoidoscopies and the follow-up of the patient, reviewed the first draft and approved the final draft of the manuscript. L-AJ participated in the planning of the manuscript, reviewed the pathology aspects of the case, provided the images and their interpretation, contributed to the drafts and approved the final version of the manuscript. J-PR planned the manuscript, contributed to file review and literature review, contributed to the manuscript drafts and approved the final version.

Funding The authors have not declared a specific grant for this research from any funding agency in the public, commercial or not-for-profit sectors.

Competing interests None declared.

Patient consent for publication Obtained.

Provenance and peer review Not commissioned; externally peer reviewed.

Open access This is an open access article distributed in accordance with the Creative Commons Attribution Non Commercial (CC BY-NC 4.0) license, which permits others to distribute, remix, adapt, build upon this work non-commercially, and license their derivative works on different terms, provided the original work is properly cited and the use is non-commercial. See: http://creativecommons.org/ licenses/by-nc/4.0/.

\section{REFERENCES}

1 Narkhede M, Arora S, Ujjani C. Primary effusion lymphoma: current perspectives. Onco Targets Ther 2018;11:3747-54.

2 Chen J, Mehraj V, Szabo J, et al. Multiple remissions of extracavitary primary effusion lymphoma treated with a single cycle of liposomal doxorubicin in a patient infected with HIV. Curr Oncol 2018;25:e592.

3 Guillet S, Gérard L, Meignin V, et al. Classic and extracavitary primary effusion lymphoma in 51 HIV-infected patients from a single institution. Am J Hematol 2016:91:233-7.

4 Simonelli C, Spina M, Cinelli R, et al. Clinical features and outcome of primary effusion lymphoma in HIV-infected patients: a single-institution study. J Clin Oncol 2003:21:3948-54.

5 Carbone A, Gloghini A, Vaccher E, et al. Kaposi's sarcoma-associated herpesvirus/ human herpesvirus type 8-positive solid lymphomas: a tissue-based variant of primary effusion lymphoma. J Mol Diagn 2005;7:17-27.

6 Dotti G, Fiocchi R, Motta T, et al. Primary effusion lymphoma after heart transplantation: a new entity associated with human herpesvirus-8. Leukemia 1999;13:664-70.

7 Boulanger E, Afonso PV, Yahiaoui Y, et al. Human herpesvirus-8 (HHV-8)-associated primary effusion lymphoma in two renal transplant recipients receiving rapamycin. $A m$ I Transplant 2008;8:707-10.

8 Ahmed O, Veeraraghavan S. Primary effusion lymphoma in solid organ transplant recipient. Chest 2016;150:758A
9 Foster WR, Bischin A, Dorer R, et al. Human Herpesvirus Type 8-associated Large B-cell Lymphoma: A Nonserous Extracavitary Variant of Primary Effusion Lymphoma in an HIV-infected Man: A Case Report and Review of the Literature. Clinical Lymphoma Myeloma and Leukemia 2016;16:311-21.

10 Aguilar C, Laberiano C, Beltran B, et al. Clinicopathologic characteristics and survival of patients with primary effusion lymphoma. Leuk Lymphoma 2020;61:1-10.

11 Song JY, Jaffe ES. HHV-8-positive but EBV-negative primary effusion lymphoma. Blood 2013:122:3712

12 Sukswai N, Lyapichev K, Khoury JD, et al. Diffuse large B-cell lymphoma variants: an update. Pathology 2020;52:53-67.

13 Saggini A, Di Prete M, Facchetti S, et al. Panniculitis-Like presentation of Extracavitary primary effusion lymphoma. Am I Dermatopathol 2020;42:446-51.

14 DePond W, Said JW, Tasaka T, et al. Kaposi's sarcoma-associated herpesvirus and human herpesvirus 8 (KSHV/HHV8)-associated lymphoma of the bowel. Report of two cases in HIV-positive men with secondary effusion lymphomas. Am I Surg Pathol 1997;21:719-24.

15 Huang Q, Chang KL, Gaal K, et al. Primary effusion lymphoma with subsequent development of a small bowel mass in an HIV-seropositive patient: a case report and literature review. Am J Surg Pathol 2002;26:1363-7.

16 Liao G, Cai J, Yue C, et al. Extracavitary/solid variant of primary effusion lymphoma presenting as a gastric mass. Exp Mol Pathol 2015;99:445-8.

17 Pantanowitz L, Wu Z, Dezube BJ, et al. Extracavitary primary effusion lymphoma of the anorectum. Clin Lymphoma Myeloma 2005;6:149-52.

18 Hook EW. Syphilis. The Lancet 2017:389:1550-7.

19 ..... PHAo C. Report on sexually transmitted infections in Canada: 2013-2014. centre for communicable diseases and infection control, infectious disease, 2017.

20 Cha JM, Choi SI, Lee JI. Rectal syphilis mimicking rectal cancer. Yonsei Med J 2010:51:276-8.

21 Mantadakis E, Samonis G. Common symptoms--different diseases: coexistence of neurosyphilis and non-Hodgkin's lymphoma. Infection 2002;30:43-5.

22 Park SY, Kang JH, Roh JH, et al. Secondary syphilis presenting as a generalized lymphadenopathy: clinical mimicry of malignant lymphoma. Sex Transm Dis 2013:40:490-2.

23 Routy B, Gopalakrishnan V, Daillère R, et al. The gut microbiota influences anticancer immunosurveillance and general health. Nat Rev Clin Oncol 2018:15:382-96.

24 Voltaggio L, Montgomery EA, Ali MA, et al. Sex, lies, and gastrointestinal tract biopsies: a review of selected sexually transmitted proctocolitides. Adv Anat Pathol 2014;21:83-93.

25 Totonchy J. Extrafollicular activities: perspectives on HIV infection, germinal centerindependent maturation pathways, and KSHV-mediated lymphoproliferation. Curr Opin Virol 2017;26:69-73.

26 Totonchy J, Osborn JM, Chadburn A, et al. Kshv induces immunoglobulin rearrangements in mature B lymphocytes. PLoS Pathog 2018;14:e1006967.

27 Nador RG, Cesarman E, Chadburn A, et al. Primary effusion lymphoma: a distinct clinicopathologic entity associated with the Kaposi's sarcoma-associated herpes virus, 1996.

28 Bestawros A, Boulassel M-R, Michel RP, et al. Hhv-8 linked to Kaposi's sarcoma, Castleman's disease and primary effusion lymphoma in a HIV-1-infected man. J Clin Virol 2008;42:179-81.

29 Costes V, Faumont N, Cesarman E, et al. Human herpesvirus-8-associated lymphoma of the bowel in human immunodeficiency virus-positive patients without history of primary effusion lymphoma. Hum Pathol 2002;33:846-9.

30 Chadburn A, Hyjek E, Mathew S, et al. KSHV-positive solid lymphomas represent an extra-cavitary variant of primary effusion lymphoma. Am I Surg Pathol 2004:28:1401-16

31 Ayers LW, Barbachano-Guerrero A, McAllister SC, et al. Mast cell activation and KSHV infection in Kaposi sarcoma. Clin Cancer Res 2018;24:5085-97.

32 Routy JP, Blanc AP, Kiegel P, et al. Dermal infiltrates of a lymphoma as a complication of implanted venous access catheter placement. Ann Oncol 1990:1:382.

33 Melenotte C, Mezouar S, Mège J-L, et al. Bacterial infection and non-Hodgkin's lymphoma. Critical Reviews in Microbiology 2020:1-18.

34 Van Voorhis WC, Barrett LK, Koelle DM, et al. Primary and secondary syphilis lesions contain mRNA for Th1 cytokines. J Infect Dis 1996;173:491-5.

35 Oksenhendler E, Boutboul D, Galicier L. Kaposi sarcoma-associated herpesvirus/ human herpesvirus 8-associated lymphoproliferative disorders. Blood, The Journal of the American Society of Hematology 2019;133:1186-90. 
Copyright 2020 BMJ Publishing Group. All rights reserved. For permission to reuse any of this content visit https://www.bmj.com/company/products-services/rights-and-licensing/permissions/

BMJ Case Report Fellows may re-use this article for personal use and teaching without any further permission.

Become a Fellow of BMJ Case Reports today and you can:

- Submit as many cases as you like

- Enjoy fast sympathetic peer review and rapid publication of accepted articles

Access all the published articles

Re-use any of the published material for personal use and teaching without further permission

Customer Service

If you have any further queries about your subscription, please contact our customer services team on +44 (0) 2071111105 or via email at support@bmj.com.

Visit casereports.bmj.com for more articles like this and to become a Fellow 